\title{
Architectural education and the idea of nature
}

\author{
C. C. Theis \\ School of Architecture, Louisiana State University, USA
}

\begin{abstract}
When various definitions of sustainable design are articulated by several leading scholars and practitioners, several conflicts and/or contradictions in underlying definitions of nature are revealed. Since all of these definitions employ the word nature, it would seem reasonable that, to understand sustainable design, students of architecture need to have more than a passing acquaintance with the multiple interpretations of the term nature. Students need a fundamental understanding of humanity's relationship to nature, but also a more holistic method of perceiving a site. Currently few schools of architecture in North America provide their students with an opportunity to obtain either of these.

Keywords: architectural education, sustainable design, ecological design, nature, site, perception, environment, place.

"If I were a young architect today looking at supposed ecoarchitecture, I wouldn't want to do it; it's a one-liner. When ecology becomes the major issue, you're left with a scientific box that does nothing for the spirit. I cannot separate the idea of the poetic and the rational. If there's not a junction, we've got merchandise, not architecture."
\end{abstract}

Glenn Murcutt

(As quoted by Raul A. Barreneche in an article reporting Murcutt's receipt of the 2002 Pritzker Prize, in the May 2002 issue of Architecture magazine.)

\section{Introduction}

There is currently a great deal of concern in the Unites States about the perceived lack of integration of sustainable design in the curricula of many schools of architecture. The National Architectural Accrediting Board (NAAB) recently 
revised the Conditions and Procedures for accreditation and was criticized by several groups, such as the Society of Building Science Educators (SBSE) and the American Institute of Architects Committee on the Environment (AIA COTE), for not addressing the issue more directly. In this paper I will present the case for two interrelated issues that I believe must be addressed in schools of architecture if students are to become more sensitive to the environment.

Of course, the concern mentioned above is not new. I remember a monthly column that appeared in seven issues of the Association of Collegiate Schools of Architecture (ACSA) NEWS during the 2000-2001 Academic Year that was intended as an opportunity for administrative officers to report on their schools' offerings in sustainable design. (The ACSA NEWS is the newsletter of the Association of Collegiate Schools of Architecture (ACSA). The monthly columns were co-sponsored by the American Institute of Architects (AIA) Committee on the Environment (COTE).) The authors (all deans or department heads of schools in North America) focused on the importance of integrating sustainable design into the core curriculum, discussed the difficulties in doing so, and offered suggestions for improving the situation.

Their suggestions ranged from increased support for research, more emphasis on multi-disciplinary collaboration, and a serious focus on how buildings work to more fundamental re-evaluations of how architecture is taught and practiced. Many of them appeared to express a concern that sustainable design remains a largely marginalized activity in many schools and much of the profession. This in spite of a special report published by the Carnegie Foundation in 1996 recommended "that architects and architecture educators assume a leadership role in preserving the environment and the planet's resources" [1].

But what exactly is meant by the term "sustainable design"? Of the seven authors of these essays, only two actually defined the term. In her column affirming Carnegie Mellon's commitment to sustainability, Vivian Loftness presented a working definition that is quite specific, but very prescriptive. For her it is "a collective process whereby the built environment achieves new levels of ecological balance through new and retrofit construction, towards the long term viability and humanization of architecture" [2]. This is not likely to inspire the "deep understanding of how buildings work" advocated by Berkeley's Harrison Fraker [3], and it doesn't really address the more "radical implications of sustainability" raised by Minnesota's Thomas Fisher. Fisher suggests that if we are "to achieve a more sustainable future, we need to start talking not just about energy-conserving techniques, but about need itself and what that means in terms of architectural education and practice" [4].

While only one of these authors actually defined "sustainable design," in reading their columns one senses the subtle but significant differences in their use of the term. The seventh author, Peter Wheelwright of the Parsons School of Design, addressed this issue directly, describing sustainability as "an umbrella term for many (often conflicting) forms of proactive attempts to mitigate humanity's transformation and negative impact on particular natural systems" and "a cultural formation still very much in the making" [5]. 


\section{Ecological design}

I use the term "ecological design" not to consciously differentiate it or preference it over others, but in a broad sense, and interchangeably with "sustainable" or "green." These are simply different terms, as Ken Yeang has suggested, for designing with nature in an environmentally responsive way [6]. In the context of architectural design, I find the term "sustainable" to be too broad; and "green" somehow too limiting, being easily confused with political and/or marketing labels. The etymological roots of the word "ecology," and the appropriateness, as William McDonough has observed, of an architectural discourse about the logic of our planet's household also influence the use of the term [7]. Nevertheless, the concerns I raise apply equally to all three terms, so I use them interchangeably in this discussion to question how students of architecture can be encouraged to practice something their instructors have difficulty defining.

Ian McHarg suggested that non-ecological design is "either capricious, arbitrary, or idiosyncratic, and...certainly irrelevant" [8]. But what is ecological design, specifically in the discipline of architecture? Sim Van der Ryn and Stuart Cowan have defined it as "simply the effective adaptation to and interaction with nature's processes" [9]. For Nancy and John Todd it is "design for human settlements that incorporates principles that are inherent in the natural world in order to sustain human populations over a long span of time" [10]. In concluding his now famous "sermon" at the Cathedral of St. John the Divine in 1993, William McDonough said:

We have to recognize that every event and manifestation of nature is "design," that to live within the laws of nature means to express our human intention as an interdependent species, aware and grateful that we are at the mercy of sacred forces larger than ourselves, and that we obey these laws in order to honor the sacred in each other and in all things. We must come to peace with and accept our place in the natural world. [11]

Renzo Piano, in discussing sustainable architecture, enjoins that: "Architecture is a second nature that is laid on top of the real one. When people who practice our profession speak of the environment they ought to remember this" [12]. And Ken Yeang, with a nod to Ian McHarg, titled his book on the ecological basis for architectural design Designing with Nature.

All of these definitions employ the word "nature," and if students of architecture are to understand ecological design, they need more than a passing acquaintance with the multiple interpretations of that word.

\section{Nature}

In an interview shortly before his death, Ian McHarg lamented that his book, Design with Nature, which, according to him, was described by the ACSA as one of the most widely read textbooks in architecture schools, has, to the best of 
his knowledge, had no effect whatsoever [13]. I would argue that if this is true an important reason might be that many architecture students, in my experience, have very little, if any, understanding of what the word "nature" means.

In her book The Language of Landscape, Anne Whiston Spirn reminds us that "nature is an abstraction, a set of ideas for which many cultures have no one name," and that "A. O. Lovejoy found sixty-six meanings of the words nature and natural in literature and philosophy from the time of the ancient Greeks to the eighteen century" [14]. Both she and I have assigned an exercise in which students must define "nature" in their own words. The responses always reveal a wide range of often contradictory and clashing perspectives; not unexpected, she points out, for a word Raymond Williams called "perhaps the most complex word in the language" [14]. And it is a word that invariably is employed by students when asked to define ecological design.

It is not within the scope of this paper to even begin to explore the relationship between the idea of nature and the discipline of architecture. Nor is it my intention to attempt to articulate an ecological design ideology based on an interpretation of our relationship to nature. What I am suggesting is that a better understanding of how the word "nature" can be interpreted would help students to sort through the complexities of new and often contradictory ideologies.

For example, in his book, The Idea of Wilderness, Max Oelschlaeger outlines the defining characteristics two contemporary views of nature:

\begin{abstract}
RESOURCE CONSERVATIONISTS believe that natural systems are no more than collections of parts; Homo sapiens is related externally to the ecomachine; the ecomachine can be engineered to produce desired outcomes and prevent undesired consequences; the market objectively determines the worth and value of all things, cultural and natural; the national per capita income accounts are the ideal measure of societal well-being; and, progress can be determined according to the utilitarian formula of the greatest good for the greatest number.

ECOCENTRICS believe that natural systems are the basis of all organic existence, and therefore possess intrinsic value; humankind is an element within rather than the reason to be of natural systems, and is hence dependent upon intrinsic value; and, ethical human actions (actions which promote the good life for humankind) necessarily promote all life on earth (preserves such intrinsic values as diversity, stability, and beauty). [15]
\end{abstract}

Without a clear understanding of such seemingly contradictory positions with regard to the natural world, students of architecture have difficulty developing a clear design intent for a project, especially if it involves multiple users groups. And, of course, there are many other views of nature ranging from those of the world's religions to ecofeminism and deep ecology.

In his ACSA NEWS column, Peter Wheelwright described two often contradictory and conflicting approaches to ecological design in schools of architecture: the "organic," which combines an activist social agenda with a 
"Wrightian" design ethic; and the "technological," which is "futurist in orientation and scientific in method." He offered a third approach emphasizing the social and natural sciences in core architecture courses. His proposal is comprised of architecture courses that "simply begin with the assumption that the affinity of architecture with natural processes is historically based, theoretically critical and a technologically inventive way to (re) inform design" is admirable, but I question the ability or even the will of many schools to effectively accomplish such a goal [16].

I argue that a fundamental understanding of humanity's relationship to nature is necessary for architecture students to learn to practice ecological design. Therefore, if a school cannot effectively encourage students to gain this understanding, it must be seen as a significant shortcoming.

\section{Site and perception}

A second closely related problem is the inability of many students to perceive a site, especially a "natural" site, as a human construct and to conceptualize its potential to be reconstructed and interpreted through architecture. Over the past decade, I have returned many times to a site that demonstrates these fundamental questions about humanity's place in nature.

The site is known as Pinecote and is part of the Crosby Arboretum in southern Mississippi. Pinecote, meaning pine shelter, consists of 64 acres in the process of being transformed from an abandoned strawberry field and pine plantation into savanna, bog, woodland, and freshwater wetland. These landscape exhibits are compressed, dramatic expressions of the natural features common to the Piney Woods of the Deep South, made famous by the writer William Faulkner. It was designed by landscape architect Ed Blake, who lived on the site for four years before beginning the transformation process. The only buildings on the site are a trailer that serves as a temporary visitor's centre, and the award-winning Pinecote Pavilion, designed by the late Fay Jones. The projects undertaken by my students have ranged from designing a new Visitor's Centre to the design of individual interpretive stations.

The question I pose is whether this unique site can establish a framework that encourages, as David Orr has suggested for all architecture curricula, "a more sophisticated and ecologically grounded understanding of place and culture" [17]. The goal is an understanding that fosters design solutions that are not abstract impositions upon the landscape, but that are derived from explorations of a specific place and the ways that built form could reveal and possibly reinforce a cultural narrative. In this case the measurable indicators would fall into two broad categories: the ability to go beyond the more traditional methods of site analysis and represent the experiential character of the site, (As, for example, discussed in Chapter 6 of Kevin Lynch's seminal text Site Planning [18]. While there is a fairly thorough discussion of "the sensed landscape," there is little reference to specific perceptual methodologies and the discussion of means of representation or "languages" is marginal at best.) and the ability to use these perceptions in the sensitive integration of buildings within the landscape. 
The stated learning objectives of most of these design studio projects included the development of skills in identifying relationships between a specific site and architectural program that would assist them in accomplishing the goals outlined above. The clearly revealed cultural construct of the site combined with programs that, in part, sought to create a framework for interpreting this unique setting should have offered opportunities to encourage these objectives. However, with a few notable exceptions, the first projects undertaken on the site failed to fully capitalize on this opportunity.

Why this failure? First, the students were not provided with an effective methodology for exploring and representing their perceptions of the physical, experiential qualities of the site. They were encouraged to essentially invent their own without any specific guidance. Secondly, even those students who were able to develop a reasonably clear perceptual model of the site were often unable to re-envision the site in a way that didn't impose a preconceived idea upon it. Their design solutions often had little relationship to the specific nature of this site and more to do with their own preconceptions about "nature."

Specifically, the students often employed traditional forms of site analysis such as overlays of contours, soil types, vegetation, drainage patterns, etc. in hopes of discovering a "natural" solution. This desire often resulted in very synthetic solutions with little reference to the sensual experience of the place. Although reading and interpreting a site is always a process of abstraction, a reliance on purely quantifiable data to define an "environment" without attending to the more qualitative attributes of "place" results in distancing the student from the experiential dimension - in the words of Christian Norberg-Schulz, the "qualitative, 'total' phenomenon, which we cannot reduce to any of its properties, such as spatial relationships, without losing its concrete nature out of sight" [19].

\section{Conclusions}

So how do we overcome these interrelated shortcomings? In the first case, I suggest that architecture students be required to take a course exploring how a society's predominant conception of nature might affect its relationship to its environment. Ideally such a course would fulfil a general education requirement, would occur as early as possible in the students' academic careers, would include an architectural component, and would be interdisciplinary in nature (possibly part of a larger "learning community").

The National Architectural Accrediting Board (NAAB) currently requires that forty percent of the courses in accredited programs must be non-professional (i.e. liberal arts and science) courses. In most schools the majority of these courses are part of a university-wide general education core, and, while I am sure there must be notable exceptions, I suspect that most of these core curricula do not require students to take courses that explore humanity's place in nature. Many institutions offer such courses, (According to the Boyer Report, William McDonough taught a required course in "Environmental Choices" that involved more than a dozen faculty and visiting lecturers from a variety of disciplines 
when he was Dean at the University of Virginia. I am not sure if it is still required or even taught. Of course, William Cronon, Neil Evernden, Leo Marx, Caroline Merchant, Donald Worster, and Michael Zimmerman (to name just a few) have taught such courses for years.) but I question how many architecture students take them.

In the second case, I believe there are two strategies to explore. First, introducing students to novel ways of perceiving and representing environments, such as those employed by artists and naturalists, may be a more productive approach.

For example, artist and naturalist Hannah Hinchman has demonstrated methodologies that encourage students to develop their own means of representation. The fact that her work is aimed at observers rather than designers of the physical environment is potentially very helpful in this context. She offers no prescriptive form of representation that would suggest an answer to students, but rather a methodology - a way of seeing. She encourages the intelligent observation of a world of "events," as opposed to the identifying of "things." In her book A Trail Through Leaves: The Journal as a Path to Place, she observes:

The idea of encouraging event perception occurred as I noticed, in my teaching, that would-be naturalist/journal-keepers are prevented from seeing the natural world. They are prevented first by categories...second, by the habit of seeing the world as dead. [20]

The second strategy would be to encourage students to view the site as a construct shaped by climatic and geologic forces (air, earth, water, and fire), and the actions of organisms, including humans - these are the "events" suggested by Hinchman. In this light, the site is seen not as a fixed, inert entity but as an evolving project. This is certainly not a new idea. Most ecologists view "disturbances" as integral processes in many ecosystems, (for an interesting discussion of this, and ecological systems in general, see Reichman [21]) and landscape architects are usually quite attuned to this way of viewing a site. In their book Inside Outside: Between Architecture and Landscape, Anita Berrizeitia and Linda Pollak construct a framework of interpretation that consists of five "operations," each of which articulates a conceptual approach to relations between architecture and landscape. All of these "operations" could be very useful tactics to employ in this strategy, but their notion of "reciprocity" is directly applicable.

The operation of reciprocity subverts the hierarchy embedded in the historical dichotomy between architecture and landscape, which has construed landscape as merely the ground on which architecture rests. It recognizes the identity of both landscape and architecture as constructed. This formulation challenges the architectural paradigm of the machine in the garden - a vision that opposes architecture's progressive alliance with technology to a nostalgic formulation of landscape as timeless and untouched nature. [22] 
By consciously encouraging students to view their work in this manner, and providing them with more effective methodologies for perceiving and representing the experiential dimension, their preconceptions may be overcome. By engaging in a dialogue with a site in an attempt to identify its potentiality its intended character or essence - the students might, in the words of NorbergSchulz, "concretize the genius loci." They would design "buildings which gather the properties of the place and bring them close to man" [23]. I believe this is very similar to David Orr's description of ecological design as "a kind of navigation aid to help us find our bearings again." He goes on to say that "getting home means remaking the human presence in the world in a way that honours ecology, evolution, human dignity, spirit, and the human need for connection" [24]. Norberg-Schulz provides a description of architecture that for me captures the essence of this task, and admirably summarizes my points.

The basic act of architecture is therefore to understand the 'vocation' of the place. In this way we protect the earth and become ourselves part of a comprehensive totality. What is here advocated is not some kind of 'environmental determinism.' We only recognize the fact that man is an integral part of the environment, and that it can only lead to human alienation and environmental disruption if he forgets that. To belong to a place means to have an existential foothold, in a concrete everyday sense. [25]

As mentioned above, more recent student studio projects on the same site have been much more successful than earlier ones. I attribute this to the new strategies that were employed.

The two problems I have identified are by no means the only shortcomings in contemporary architectural design education that inhibit students' abilities to design ecologically, and I do not claim that my proposed changes are a panacea. But I do believe that they might provide some of the tools necessary to foster the "more sophisticated and ecologically grounded understanding of place and culture" suggested by David Orr. They might also help to encourage Glenn Murcutt's "junction" of "the poetic and the rational."

\section{References}

[1] Boyer, E. L., \& Mitgang, L.D. Building Community. Carnegie: Princeton, p. 43, 1996.

[2] Loftness, V. Carnegie Mellon is Committed to Sustainability - What About You? ACSA NEWS, 30(2), p. 6, 2000.

[3] Fraker, H. Is Sustainable Design still Marginalized in the Schools? ACSA NEWS, 30(3), p. 10, 2000.

[4] Fisher, T. The Needs of Sustainability. ACSA NEWS, 30(1), p.6, 2000.

[5] Wheelwright, P. M., Texts and Lumps: Thoughts on Science and Sustainability. ACSA NEWS, 30(4), p. 5, 2000.

[6] Yeang, K. Designing with Nature. McGraw-Hill: New York, p. 1, 1995. 
[7] McDonough, W., Design, Ecology, Ethics, and the Making of Things. Theorizing a New Agenda for Architecture, ed. K. Nesbitt, Princeton Arch. Press: New York, p. 402, 1996.

[8] McHarg, I. L., Ecology and Design. Ecological Design and Planning, ed. G. F. Thompson \& F. R. Steiner, Wiley: New York, p. 321, 1997.

[9] Van der Ryn, S. \& Cowan, S., Ecological Design, Island Press: Washington, p. 18, 1996.

[10] Todd, N. J. \& Todd, J., From Eco-Cities to Living Machines, North Atlantic: Berkeley, p. 1, 1994.

[11] McDonough, W., Design, Ecology, Ethics, and the Making of Things. Theorizing a New Agenda for Architecture, ed. K. Nesbitt, Princeton Arch. Press: New York, p. 407, 1996.

[12] Piano, R., Logbook, Monacelli: New York, p.248, 1997.

[13] McHarg, I. L., Why is Architecture Oblivious to the Environment? Design Outlaws on the Ecological Frontier, ed. C. Zelov \& P. Cousineau, Knossus: Cape May, p. 54, 1997.

[14] Spirn, A. W., The Language of Landscape, Yale: New Haven, p.248, 1998.

[15] Oelschlaeger, M., The Idea of Wilderness, Yale: New Haven, pp. 287, 289, \& 294, 1991.

[16] Wheelwright, P. M., Texts and Lumps: Thoughts on Science and Sustainability. ACSA NEWS, 30(4), pp. 5-6, 2000.

[17] Orr, D., Architecture, Ecological Design, and Human Ecology. Paradoxes of Progress: Architecture and Education in a Post-Utopian Era (Proceedings of the $89^{\text {th }}$ ACSA Annual Meeting), ACSA: Washington, p. 23, 2001.

[18] Lynch, K. Site Planning, 3rd ed. K. Lynch and G. Hack, MIT Press: Cambridge, MA, pp. 153-192, 1998.

[19] Norberg-Schulz, C., The Phenomenon of Place. Theorizing a New Agenda for Architecture, ed. K. Nesbitt, Princeton Architectural Press: New York, p. 414, 1996.

[20] Hinchman, H., A Trail Through Leaves: The Journal as a Path to Place, Norton: New York, p.150, 1997.

[21] Reichman, O. J. Konza Prairie: A Tallgrass Natural History, University Press of Kansas: Lawrence, KS, 1987.

[22] Berrizbeitia, A. \& Pollak, L., Inside Outside: Between Architecture and Landscape, Rockport: Gloucester, MA, pp. 11-12, 1999.

[23] Norberg-Schulz, C., The Phenomenon of Place. Theorizing a New Agenda for Architecture, ed. K. Nesbitt, Princeton Architectural Press: New York, p. 426, 1996.

[24] Orr, D., Architecture, Ecological Design, and Human Ecology. Paradoxes of Progress: Architecture and Education in a Post-Utopian Era (Proceedings of the $89^{\text {th }}$ ACSA Annual Meeting), ACSA: Washington, p. 30, 2001.

[25] Norberg-Schulz, C., The Phenomenon of Place. Theorizing a New Agenda for Architecture, ed. K. Nesbitt, Princeton Architectural Press: New York, p. 426, 1996. 